\title{
TI TESER OM MUSEET I SAMFUNDET
}

\section{Bruno Ingemann}

1. Museet kan fortalle historier med autentiske ting

2. Autentiske ting presenteres $i$ en ny sammenhang

3. Ting kan gestalte en astetisk oplevelse

4. Estetisk oplevelse kan skabes af 'teksten' og af den besogende

5. Ting kan ses som et kunstnerisk udtryk - en fortalling

6. En fortalling ma kunne skabe mentale billeder

7. Samfundets fortallinger bygger pa myter og symboler

8. Museet ma kommunikere samfundets fortallinger

9. Museet er $i$ samfundet

10. Samfundet er $i$ museet

De ti teser er meget centrale. At indsamle, dokumentere, bevare, formidle etc. er vigtige områder men her ses museets rolle $i$ samfundet $i$ hoj grad ud fra en formidlingssynsvinkel-det er altsa den rolle som museet kan spille for den almindelige besøgende som bade bliver en forbruger der skal tilfredsstilles men som isar er en partner for dialog. En partner som man ma respektere og tage alvorligt. Til hver tese er knyttet en eller flere noter som uddyber tesen. Det er altsa hensigten at tydeliggore museets rolle i samfundet i en meget kort form.

\section{MUSEET KAN FORTELLE} HISTORIER MED AUTENTISKE TING

1.1 Museet i bestemt form gør det faktisk umuligt at fortsætte. Men i det folgende har jeg fokuseret på kulturhistoriske museer (men her er alt fra mindre lokalhistoriske museer til Nationalmuseet - men også 'ikke-museer' som Lejre Forsøgscenter).
1.2 Begrebet autentisk er tricky. På den ene side bliver det brugt som betegnelse på enestående genstande som er fra den rette tid og rette sted, fx. solvognen. Men Vasström (1999) udvider begrebet fra at handle om genstande til i stedet at handle om en autentisk 'stemning'.

1.3 Det er problematisk i overhovedet at se det autentiske som værdifrit. Det er 
48 meget bundet til en materiel kultur og i andre lande er det helt andre forestillinger der betyder noget. Det autentiske er i stedet det som gentages. Shinto-templerne i Japan rives ned hvert 20ende år og genopbygges. $\mathrm{Og}$ det nye hus er lige så autentisk som et gammelt. Det autentiske ligger altså $\mathrm{i}$ at huset bygges ud fra gamle håndværkstraditioner.

1.4 Anne Sofie Becker (1990) laver en skelnen mellem den præsentative og den diskursive udstillingstype. Den presentative som udstiller genstandene som de er med uendelige mange 'tomme pladser' der skal udfyldes af den besøgende. Den diskursive type som for Becker etablerer 'homogene ordner, sammenhængende lukkede systemer, hvis enkeltdele altid må indordne og tilpasse sig helheden...' (1990:81).

1.5 Jeg har her truffet et valg mellem det 'præsentative' og det 'diskursive'. Ved at opbygge en dikotomi mellem de to begreber skabes der både en klarhed og der skabes et slør. Det 'diskursive' er jo netop ikke én ting. Der kan fortælles på mange forskellige måder med mange forskellige hensigter. Det er afgørende at museet skal fortælle historier. Det særlige og specielle for museet er at det har ting.

1.6 Ting er museets kronjuveler. Den besøgende forventer de er der - også selv om den besøgende lægger vægt på udstillingens tekster og billeder. Man kan kalde det for 'flow-of-kindness' - at tingene bare er der! (Ingemann 1999:168).

\section{AUTENTISKE TING PRESENTERES I EN NY SAMMENHENG}

2.1 En kulturhistorisk ting har sit eget liv som brugs- eller kultgenstand. Den tages ud af $\sin$ brugsfunktion og ud af sin tid og placeres ind $i$ en ny tid og et nyt rum og får en ny funktion. Michael Braxendall (1991:34) finder at der er tre kulturer der mødes i udstillingen - for det første de ideer, værdier og intentioner der ligger $\mathrm{i}$ den kultur hvori artifakten skabes og kommer fra. For det andet er der de ideer, værdier og hensigter der ligger i den kultur og hos den museumsinspektør der arrangerer udstillingen. $\mathrm{Og}$ for det tredie er der beskueren selv med hele sin kulturelle bagage af usystematiske ideer, værdier og igen meget specifikke formål. $\mathrm{Og}$ han bruger eksemplet med at udstille en mbulu-ngulu maske sammen med Picasso's maleri fra 1907 inspireret fra og af den slags masker 'The effect of visual similarity is to accent difference.' (Braxendall 1991:40).

2.2 Susan Vogel peger på 'Almost nothing displayed in museums was made to be seen in them. Museums provide an experience of most of the world's art and artifacts that does not bear even the remotest resemblance to what their makers intended. This evident fact lies at the very heart of museum work (which is a work of mediation) and should be a preoccupation of all museum professionals, though most museum visitors seem practically unaware of it.' (1991:191).

2.3 Marcel Duchamp udstillede i 1917 den berømte 'Fontain' hvor han tog den massefremstillede pissoir kumme og placerede den $i$ et galleri. Det eneste han gjorde yderligere var at signere den 'R. Mutt'. Hermed indledte han diskussionen om værket som autentisk eller konteksten der bestemte om det udstillede kunne ses som autentisk kunst. Men det særlig interessante er at han ikke fik ideen ved at se på 
pissoiret $\mathrm{i}$ brug på et toilet - nej han så den $\mathrm{i}$ udstillingsvinduet hos sanitetsfirmaet Mott Works på Fifth Avenue i New York. Det var altså fra udstilling $\mathrm{i}$ en kontekst til udstilling $i$ en anden kontekst at bevægelsen var. I udstillingsvinduet var pissoiret allerede løftet ud af sin brugskontekst.

\section{TING KAN GESTALTE EN AESTETISK OPLEVELSE}

3.1 Jeg vil sige at på et første procesniveau, så må enhver udstilling kunne aflæses som ren $x$ stetik. Det betyder at der i selve udstillingen lægger op til et æstetisk blik. Det er ikke genstanden i sig selv der nødvendigvis besidder kraften til at kunne aflæses æstetisk - men det bliver hele iscenesættelsen der afgør om det bliver muligt. Det æstetiske blik er her set som en søgen efter det smukke, det tiltalende, det kuriøse, det pittoreske, det smagfulde, det indsmigrende - en søgen efter ligheder med noget man kender (Ørskov 1966:67).

3.2 Peter Cornell skriver i sin bog Saker. Om tings synlighet at museet er synlighedens laboratorium. Som zone for synlighed opfordrer museet til glubsk og hengivent betragten. I mødet med genstanden på museet står et rigt og nuanceret sprog til rådighed, mens vi udenfor står ejendommeligt stumme overfor livsverdens dagligdags ting som om deres form og nærvær er uvedkommende og uden mening. Cornell mener at det er gennem filosofens, poetens og kunstnerens blik, eller gennem barnets øjne at tingene bliver synlige på ny: de får tingen til at tale og os til at tale om tingene, om voksdugen, køkkentøjet, uret, trappen eller et glas vand (1993:10). Men jeg synes Peter Cornell er alt for venlig; selv tingene på museet kan opleves uvedkommende og uden mening og har brug for et åbent blik som kan gøre tingene synlige på ny - eller for første gang.

3.3 Det vender på en måde igen tilbage til det autentiske. Den autentiske genstand bliver set som en modsætning til 'imitationer', 'kopier' eller 'forfalskninger' - altså en bundethed til den fysiske genstand, dens produktion, materialer og brug.

Men Dean MacCannell mener at det ikke-autentiske skaber en slags samlende bevidsthed som definerer den moderne tids ånd. Altså at den søgen efter autenticitet afhænger af den folelse af ustabilitet og ikke-autenticitet som karakteriserer den moderne bevidsthed. Man kan sige at MacCannell forandrer kriteriet for autenticitet fra genstanden i sig selv - til den måde hvorpå det opleves! Med andre ord: for at have en autentisk oplevelse er det lige så vigtigt at artifakten bliver ordentligt præsenteret som det er at det har den rette herkomst. Dermed kan man ikke lave modsætningen imitation - virkelig. Sandheden ligger ind imellem, som det man kan kalde simulation. Lisa C. Roberts stiller spørgsmålet: ,And if the experience is properly simulated - in other words, if the corrects effect are reproduced in the lived body - does it matter that the props are "faked". Og Roberts overvejelser fører til det semiotiske landskab og fortællingen. Betydning ligger ikke i tingen i sig selv - men i det som eksterne tegn lægger til genstanden og dermed sker yderligere et skift i synet på autenticitet og genstand. Beskueren kan opleve genstanden - men hvad der betinger autenticiteten er ikke genstanden i sig selv, det er ikke beskueren 
50 i sig selv - men det er også den 'setting' som genstanden er placeret $i$ og som beskueren kan opleve.

\section{ESTETISK OPLEVELSE KAN SKABES AF 'TEKSTEN' OG AF $D E N$ BESØGENDE}

4.1 En æstetisk oplevelse - er derimod noget meget mere omfattende. Man kan se Oplevelsen som et område der består af fire felter: Værdier, Emotioner, Viden og Handling. Den æstetiske oplevelse går altså lang udover æestetik som 'det skønne'. Hvis noget for en beskuer skal kunne understøtte en æstetisk oplevelse så er det noget som både bekræfter den indsigt som ligger i de fire felter - og dels noget som udfordrer dem og altså tilfører noget som er nyt og overraskende.

4.2 Den æstetiske oplevelse kan ses som bestående af fire felter: viden, emotion, værdi og handling.

Videns-feltet drejer sig både om at få ny viden og at bruge den viden som præsenteres for den besøgende og som er tilstede i situationen - det kan være faktuel viden som er forankret $i$ en situation og $i$ en kontekst. Men det drejer sig også om den besøgendes tidligere viden som er aktiv i situationen.

Emotions-feltet kan ses som forbindelsen

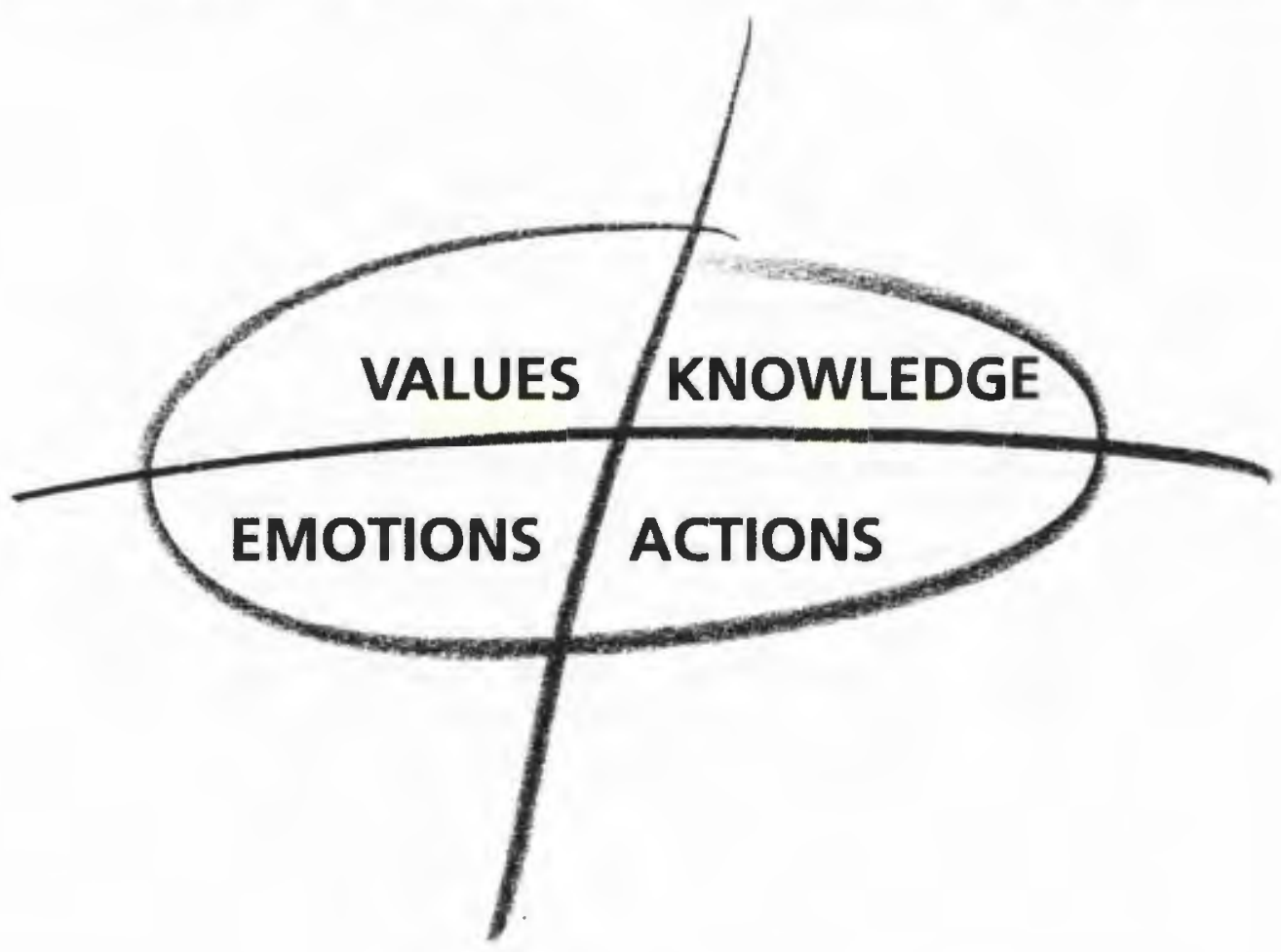


mellem mennesker, natur og fysiske objekter i sig selv og i de sociale relationer og handlinger der er forbundet hermed. På museet skabes disse forbindelser gennem repræsentationer og det æstetiske spiller derfor en stor rolle. Det æstetiske kan være kedeligt eller provokerende.

Vardi-feltet er relateret til kollektive og personlige værdisystemer, normer og moral. Disse værdier spiller en stor rolle som grundlag for relevans og umiddelbar reaktion på udstillingen.

Handlings-feltet har at gøre med hverdags aktiviteter fra at være beskuer til at foretage informerede valg om konkrete oplevelser. På museet spiller kroppen en stor rolle. Den konkrete vandring i virkelige rum; berøring af virkelige genstand; interaktivitet $i$ forhold til skærme og knapper etc. (Gjedde \& Ingemann 1999).

De fire oplevelsesfelter kan aktiveres men er meget afhængig af beskuerens mål: fra ren underholdning, 'fà tiden til at gå' til en form for informel 'læring'. Det er museet der kan planlægge at aktivere én eller flere dele af oplevelsesfelterne.

4.3) Stanly Fish (1980) mener at der slet ikke findes nogen 'tekst' (altså genstande, rum, billeder, skrevne tekster) og Edwina Taborsky (1990) mener at 'teksten' konstrueres $\mathrm{i}$ en social sammenhæng. Det er altså i beskuerens møde mellem udstillingen og teksten at betydning skabes.

\section{TING KAN SES SOM ET KUNSTNE- RISK UDTRYK - EN FORTELLING}

5.1 Genstande må ses som et kunstnerisk udtryk - en fortælling. Hvor æstetik måske er den enkle og nemme bro mellem genstande og beskueren - så er det også en temmelig begrænset bro hvis museet ønsker at formidle noget som også for den besøgende kan løfte sig op fra det ubevidste og i-tale-sættes.

Skal noget i-tale-sættes kræver det at genstandene på museet sættes ind i en kontekst hvor det bliver muligt at aflæse genstande, rum, forløb, tekster - som en bevidst fortælling.

5.2 En fortælling må indeholde seks elementer: Resumé: Hvad drejer der her sig om; Indledning: Hvem, hvad, hvor, hvornår? Udvikling: Hvad skete der så? Evaluering: Og hvad så? Løsning: Hvad skete der tilsidst? Det er altså både en narrativ struktur men det er også brugen af billeddannende og emotive sprog (Gjedde 1999:10).

5.3 En fortælling er ikke blot noget der ligger i 'teksten' - det er et iboende træk hos mennesker at vi omsætter oplevelser og forstår dem som indre narrativer - så selv når der ikke i 'teksten' er en narrativ struktur - så vil vi have en tilbøjelighed til at fortælle om vores personlige oplevelse i en narrativ struktur (Gjedde 1999:16).

5.4 På Københavns Bymuseum har man i en montere placeret et påkørt pindsvin, en mobiltelefon, et kontokort og et sæt bilnøgler. Denne lidt absurde kombination af genstande fra livet ved motorvejen ledsages af en lakonisk og tørt konstaterende tekst: 'Naturen må vige for udbygningen af vejnettet. Afstanden mellem arbejde og hjem bliver større' - så har man prøvet at skabe en fortælling der både indholder en række tomme pladser der skal udfyldes af beskueren - men som samtidig også indeholder en rækker værdier, emotioner og viden som beskueren genkender, er enig eller uenig $i$, men som er en betydningsskabende akrivitet. 


\section{EN FORTALLING MA KUNNE SKABE MENTALE BILLEDER}

6.1 Genstande og tekster kan skabe mentale billeder - som altså er indre billeder for beskueren. Det lille eksempel fra Bymuseet kan ses som en måde hvorpå der skabes mentale billeder. De enkelte dele fungerer som metonymer på noget større - og gennem den ironiske distance i reksten sammen med genstandene skabes et mentalt billede som er meget komplekst. Men samtidig bruges elementer symbolsk til at fortælle en bestemt historie.

6.2 Forudsætningen for at skabe mentale billeder er at lægge vægt på narrativitet. Det er også at bruge 'sproglige' teknikker hentet fra fiktionen. Det er i sammenstødet mellem genstande og genstande og teksten at det samlede mentale billede etableres.

\section{SAMFUNDETS FORTALLINGER BYGGER PA MYTER OG SYMBOLER}

7.1 Vi kan starte med et konkret eksempel. På Arbejdermuseets udstilling om 1950'eren Fart og tempo er der udstillet konkrete og autentiske ting og på dette helt nære niveau er det en fremvisning af en tids og en kulturs materielle ting. Men samtidig bruges disse konkrete ting til at fremstille en myte om fremskridt. Roland Barthes anskuer denne skiften mellem at se tingene i sig selv og så det at se myten med at køre bil og sidde og kigge ud på landskabet gennem bilruden: 'Jeg kan indstille mine øjne på landskabet eller på ruden. Snart opfatter jeg ruden som nærverende og landskabet som noget fjernt. $\mathrm{Og}$ snart opfatter jeg ruden som noget gennemsigtigt og landskabet som noget, der har dybde. Men resultatet af denne skiften er konstant: ruden er for mig på en gang nærværende og tom, indholdsløst, landskabet på uvirkeligt og karakteriseret af fylde (Barthes 1957:159). Man kan se tingene fra 50'erne og man kan se myten om fremskridt og velfærd.

7.2 En myte er en historie hvorved en kultur forklarer og forstår nogle aspekter ved virkeligheden eller naturen. Primitive myter er om liv og død; mennesker og guder; ondt og godt. Vores sofistikerede myter er om maskulinitet og feminitet; om familie, om succes; om tid; om videnskab.

7.3 Det lille eksempel fra Københavns Bymuseum kan også ses som et udtryk for en myte. Det kan ses som en myte om hastighed og tid og som et symbolsk udtryk for egocentrerede værdier og ønsket om at have $\mathrm{i}$ forhold til at være (Fromm 1976/81).

7.4 Ingen myter er universelle i en kultur. Man kan tale om en dominerende myte, men der er også modmyter og forandringer af myter $i$ en evolutionær proces hvor nogle dele af kæder af relaterede konsepter forskydes og andre tilføjes.

7.5 Jung ser traditionelle myter (Ødipus, Orfeus \& Eurodike etc.) som mytologiske motiver og han finder en mængde sammenfaldende træk i en række kulturers myter. Dels ved at myterne er væsentlige analogier. Dels ved at skabe teorien om det kollektive ubevidste og arketyper: 'They are without known origin; and they reproduced themselves in any time and any place of the world.' (Jung 1994:69). 


\section{MUSEET MA KOMMUNIKERE SAMFUNDETS FORTAELLINGER}

8.1 Samfundets fortællinger er jo herligt meget komplekse. Det betyder at der er mange fortællinger der er muligt. På små lokalhistoriske museer kan man have en meget tæt relation til de besøgende og dermed være meget målrette $\mathrm{i}$ sin formidling og i sin konstruktion af historien - altså være modtagerfokuseret. På store museer som i princippet er for 'alle' er det ikke nogen mulig strategi. Til gengæld må de store museer så $\mathrm{i}$ endnu højere grad være fokuseret på at være afsenderfokuseret. Det betyder at tage et ansvar for at formulere samfundets fortællinger og tillade sig at være autoritativ.

8.2 Samfundets forrællinger er ikke bare. De skabes $\mathrm{i}$ et kompliceret kredsløb mellem forfattere og massemedier og forskere. Det er måske ikke museets folk i sig selv der kan skabe eller konstruere de rette fortællinger. Det er måske vigtigt at gå uden for de 365 menneskers kreds og undersøge og få følsomme seismografiske mennesker til at komme med hovedtrækkene i samfundets historie. Det er mødet mellem det nye og det kendte og især balancen mellem dem.

\section{MUSEET ER I SAMFUNDET}

9.1 Jeg skrev i starten at de ti teser ikke kunne omfatte alle museer $\mathrm{fx}_{\mathrm{x}}$ ikke kunstmuseer. Det er jeg ikke helt sikker på passer. Jeg mener faktisk at de ti tese-sætninger holder også i relation til kunstmuseer - men at der så til gengæld skal skrives og tænkes andre diskussioner (og dermed nogle andre noter) som ligger skjult i de så uskyldige ord i de ti sætninger.
9.2 Elaine Heumann Gurian (1999:65) mener at museer $i$ fremtiden ikke bliver defineret ved at de har ting 'but from "place" and "storytelling in tangible sensory form," where citizenry can congregate in a spirit of cross-generational inclusivity and inquiry into memory of our past, a forum for our present, and aspirations for our furture."

9.3 David Anderson (1997:xii) ser museets rolle som 'læring' ved at den besøgende opnår evnen til at føle og tænke. Og han citerer den svenske parlamentariske kommission for museer som i 1994 skrev: 'There are those who claim that museums are mostly for fun, or that preservation of artifacts from the past is an end in itself. We argue that museums are in the service of society and consequently must offer both learning and entertainment, but the single most important objective of memory is to help us to learn, as individuals in society.'

9.4 John Falk ser museet i den meget individualiserede verden med livslang uddannelse 'As free-choice learning comes to represent an ever greater percentage of the total learning an individual does in his or her lifetime, museums promise to become ever more important and ever more accepted as vital links within the educational infrastructure of the community.' (1999:273). Men det betyder så også noget for hvordan museet vælger at spille den rolle.

9.5 En central rolle $f_{x}$ for Arbejdermuseet er at skabe genkendelse. De besøgende skal kunne genkende genstande og rum som deres egne. Man kan sige at nostalgi og genkendelse nogle gange er det centrale mål for museet. (Vasström 1999).

9.6 Albert William Levi (1995:344) ser 
54 på museets forskellige institutionelle roller:

- som varehus

- som montre og vogter om det æstetisk værdifulde i samfundet

- som et uundværligt instrument i den store opgave at 'danne folk'

Og han ser på fire forskellige strategier museet kan vælge:

- ideen om museet som en samling af enestående 'værker' til æstetisk nydelse

- ideen om museet som agent for kulturhistorien

- ideen om museet som advokat for museumsdisciplinerne

- ideen om museet som humanistisk institution med vægt på kommunikation (form og indhold), kontinuitet (tradition) og social kritik.

\section{SAMFUNDET ER I MUSEET}

10.1 Kan samfundets borgere finde dele af deres virkelighed repræsenteret på museet? Det kan man fx på Arbejdermuseet på en meget direkte måde. Men kan man også det på fx Nationalmuseet? Måske er afstanden mellem den besøgendes personlige virkelighed og museets fremstilling af virkeligheden så stor at det ikke er identifikation eller nostalgi der er en drivende kraft. Derfor bliver det vigtigt at den besøgendes personlige virkelighed kan forbindes til noget som er større end genkendelse af genstande og rum - og dermed bliver det vigtigt for den besøgende at kunne relatere sig til symboler og myter.

10.2 Når samfundet er defokuseret, individualiseret og værdirelativ så fører det direkte ind i kulturen og dermed også ind i museet. Det kan være en meget stor modsigelse til disse 10 teser. Men sådan opfatter jeg det ikke. Man kan måske ikke fortælle den store fortælling. Men man kan fortælle mange små fortællinger. Det diskursive er meget mere end én samlet historie. På samme måde som de postmoderne medier er individualiserede og interaktive - så kan museet også skabe historier der kan bruges individualiseret og interaktivt. Men forudsætningen for at noget kan bruges individualiseret og interaktivt for at aktivere hele oplevelsesfeltet er - at der findes små historier hvor det er muligt at finde identifikation, finde emotivt 'sprog' og mentale 'billeder' og som trækker på stærke symboler og myter.

Paper fremlagt på Museologisk Netværks seminar den 24.-25. juni 1999.

\section{LITTERATUR}

Anderson, David (1997): A Common Wealth. Museum and learning in the United Kingdom, Department of National Heritage.

Barthes, Roland (1957): Mytologier, Rhodos.

Becker, Anne Softe (1990): 'Museets ting og udstillings orden' in Antropologi nr. $21 / 22$.

Braxendall., Michael (1991): 'Exhibiting Intention: Some Preconditions of the Visual Display of Culturally Purposeful Objects' in Karp, I. \& Lavine, S.D.: Exhibiting Culture, Washington: Smithsonian Institution Press, p. 31-41.

Cornell, Peter (1993): Saker. Om tingens synlighet, Stockholm: Gidlunds.

Falk, J.H. (1999): 'Museums as institutions for Personal Learning' in Dadalus vol. 128, no.3, 1999. p.259-275.

Fish, Stanly (1980): Is there a Text in This Class, Cambridge.

Fromm, Eric (1976/81): To have or to be?, New 
York: Bantam Books.

Gjedde, Lisa: Fortellingens dimensioner, ph.d. afhandling 1999.

Gjedde, Lisa \& Ingemann, Bruno (1999): 'In the beginning was the Experience', paper præsenteret ved den 14. nordiske konference for massekommunikations forskning i Göteborg 14.-17. august 1999.

Gurian, Elaine Heumann (1999): 'What is the Object of this Exercise? A Meandering Exploration of the Many Meanings of Objects in Museums' in Dedalus vol. 128, no.3, 1999. p.163- 183.

Ingemann, Bruno (1999): 'Det er helt vildt! - om læsestrategier og reception af en udstilling' in Nordisk Museologi 1999 nr. 1, p. 155-172.

Jung, C.G. (1964): Man and his Symbol, London: Arkana.

Levi, Albert Willimam (1995): 'The Art Museum as an Agency of Culture' p.331-346) in Neill, Axel \& Ridley, Aaron: Arguing about Art, New York: McGraw-Hill.

Roberts, Lisa C. (1997): From Knowledge to Narrative. Educators and the Changing Museum, Smithsonian Institution Press.

Tabowsky, Edwina (1990): 'The discursive object' p. 50-77 in Pearce, Susan (ed.): Objects of Knowledge, London: The Athlone Press. Vasström, Anette \& Floris, Lene (1999): På Museum, Roskilde Universitetsforlag. Vogel, Susan (1991): 'Always true to the object, in our fashion' in Karp, Ivan \& Lavine, Steven D. (ed): Exhibiting Culture. The Poetics and Politics of Museum Display, Smithsonian Insitution Press.

Ørskov, Willy (1966): Aflesning af objekter, København: Borgen.
SUMMARY

Ten theses on the Museum in society

1) The museum can tell stories with authentic objects

2) The authentic objects can be presented in a new context

3) Objects can construct an aesthetic experience

4) An aesthetic experience can be created by the "text" and the visitor

5) Objects can be seen as an artistic expression - a narrative

6) A narrative may create mental images

7) The narrative of society is built upon myth and symbols

8) The museum may communicate the narratives of society

9) The museum is in society

10) Society is in the museum.

Bruno Ingemann, ph.d., lektor ved Kommunikation, Roskilde Universitetscenter.

Adr. Kommunikation, Roskilde Universitetscenter, Po.Box 260, DK-4000 Roskilde

$\mathrm{Fax}+4546743075$

e-mail:bruno@ruc.dk 